\title{
Too Sleepy for Surgery
}

\author{
Neil S. Cherniack
}

New Jersey Medical School, Newark, N.J., USA
In this journal, van Kralingen et al. [1] assert that sleep complaints and disordered breathing are common in the obese and can lead to significant perioperative complications. Although the patients studied were being evaluated for weight reduction surgery, the findings are relevant to all sorts of surgery performed in the very obese. In the study of Van Kralingen et al. [1], all of the patients had a body mass index $>30$ and all but 15 had a body mass index $>40$.

It is important to confirm their results because there are several potential problems with the study itself.

The criteria used in the study to diagnose sleep-disordered breathing may not be optimal. It is troubling that sleep complaints were as frequent in those without sleep disordered breathing. Particularly worrisome is the finding that hypersomnolence and observed apneas are about the same in the two groups. Sleep-disordered breathing is rather arbitrarily defined. It would have been important to know the severity of the disturbances in the sleep-disordered breathing group and whether cardiac arrhythmias were ever observed. Besides the one study by Rennotte et al. [2] mentioned by the authors there is little information on the frequency or severity of the perioperative risks in the patients with sleep-disordered breathing. It is unfortu- nate that no control group of subjects was studied by the authors. They have also provided no data on whether or not the patients they studied received surgery and if they had complications.

The authors suggest that respiratory monitoring might be needed in the very obese and that continuous positive airway pressure may be necessary in patients with sleepdisordered breathing to prevent complications. These suggestions may be valid and deserve more investigation to examine whether we have at present the tools to predict which obese patients are likely to encounter difficulties with surgery because of sleep apnea.

\begin{tabular}{|c|c|}
\hline References & $\begin{array}{l}1 \text { van Kralingen KW, de Kanter W, de Groot GJ, } \\
\text { Venmans BJW, van Boxem T, van Keimpema } \\
\text { ARJ, Postmus PE: Assessment of sleep com- } \\
\text { plaints and sleep-disordered breathing in a con- } \\
\text { secutive series of obese patients. Respiration } \\
\text { 1999;66:312-316. } \\
2 \text { Rennotte MT, Baele P, Aubert G, Rodenstein } \\
\text { RO: Nasal continuous positive airway pressure } \\
\text { in the peri-operative management of patients } \\
\text { with obstructive sleep apnea submitted to sur- } \\
\text { gery. Chest 1995:107:367-374. }\end{array}$ \\
\hline
\end{tabular}

Neil S. Cherniack, MD

Office of the Dean

UMDNJ - New Jersey Medical School

185 South Orange Avenue, Newark, NJ 07103-2714 (USA)

Tel. +1 973972 7937, Fax +1 9739727104 